\title{
ARTIKELEN
}

\section{Wetgeving in de responsieve rechtsstaat}

\author{
M. Scheltema
}

\section{Inleiding}

De democratische rechtsstaat is bedoeld om de burger zo goed mogelijk te dienen. De burger staat daarin centraal: zijn inzichten en belangen moeten richtinggevend zijn, en niet die van de overheid, van een heerser of van de machtigen in de samenleving.

De burger ervaart het vaak anders. De overheid ziet hij dan als bureaucratisch bolwerk, waarin ambtenaren zich achter de regels verschuilen. Juristen kunnen hem wel goed uitleggen hoe belangrijk regels in een rechtsstaat zijn, regels die zonder aanzien des persoons toegepast worden. Maar toch: wanneer de rechtsstaat voor de burger geen werkelijkheid wordt, is het doel niet bereikt. Dan voelt de burger niet dat hij serieus wordt genomen, en verliest hij zijn vertrouwen in de overheid en in de democratische rechtsstaat.

Hoe kan het gebeuren dat de mooie constructie van de rechtsstaat in de praktijk niet zichtbaar wordt? Voor het beantwoorden van die vraag draagt het recente WRR-rapport Weten is nog geen doen belangrijke inzichten aan. ${ }^{1}$ Ik zou in lijn daarmee het antwoord als volgt willen formuleren: de vormgevers van de rechtsstaat hebben een verkeerd beeld van de burger voor ogen. Zij hebben de rechtsstaat gemaakt voor een door hen bedacht modelbeeld van de burger. Dat is een burger die steeds rationeel handelt, voldoende kennis heeft om goede keuzes te maken en voldoende redzaam is om met de regels en met de overheid om te gaan. Dat abstracte beeld klopt niet. Burgers verschillen enorm van elkaar wat betreft temperament, kennis en ervaring. Het vermogen om voortdurend de nodige informatie te vergaren en op grond daarvan rationeel te handelen heeft bijna niemand, zo volgt uit de beschouwingen van de Wetenschappelijke Raad voor het Regeringsbeleid (WRR).

Tot op zekere hoogte beseffen wij, juristen, dat wel. Dat ieder geacht wordt de wet te kennen, is de wensdroom van de jurist die aan de rechtsstaat bouwt, maar is duidelijk meer een wens dan een realiteit. Wij hebben dat adagium toch erg nodig om het systeem in ons denken sluitend te houden.

Het is de verdienste van het WRR-rapport Weten is nog geen doen om meer systematisch te onderbouwen dat het modelbeeld van de burger niet klopt. De WRR laat vanuit de theorie en vanuit de empirie zien dat de rechtsstaat eisen aan de 
burger stelt, waaraan die burger niet, of althans lang niet altijd kan voldoen. De burger mist in veel gevallen de kennis die nodig is om goed met regels om te gaan. Maar daar komt bij - en daarop legt de WRR sterk de nadruk - dat die kennis alleen onvoldoende is. Het doenvermogen, zoals de WRR het noemt, is evenzeer van groot belang. De burger moet de redzaamheid hebben om goed met regels te kunnen omgaan. Weten is nog geen doen: om in de rechtsstaat te kunnen functioneren zijn ook overzicht en doorzettingsvermogen nodig, en moet men zich niet door stress of tegenslag van de wijs laten brengen.

Misschien geldt hier voor juristen wat economen al langer geleden hebben ontdekt. De rationele actor die over voldoende relevante informatie beschikt om goede keuzes te maken, is geen goede typering van het economisch handelen van mensen. Economische theorieën en modellen die uitsluitend daarop waren gebaseerd, moesten dan ook worden herzien toen gedragswetenschappelijke inzichten hun intrede in de economie deden. ${ }^{2}$

Iets soortgelijks moet gelden bij de vormgeving van de rechtsstaat en meer algemeen van het recht. De responsieve rechtsstaat zou men kunnen typeren als de rechtsstaat die zich richt op de burger zoals die echt bestaat. Dat is de burger die zo veel mogelijk zijn eigen keuzes wil maken, maar die niet altijd slim, daadkrachtig en rationeel reageert. Men kan hiertegenover de bureaucratische rechtsstaat stellen als een constructie die vanuit het klassiek juridische perspectief voldoet aan de eisen van de rechtsstaat, maar die ervan uitgaat dat de burger steeds over adequate bureaucratische vaardigheden en veel redzaamheid beschikt. De responsieve rechtsstaat erkent dat dit beeld van de burger niet klopt, en het doenvermogen van de burger overschat. Hij neemt de echte burger serieus, wat niet betekent dat de burger altijd krijgt wat hij wenst. Het betekent wel dat de overheid het voor de burger mogelijk maakt haar optreden als rechtvaardig te aanvaarden. Voor het vertrouwen in de overheid is dit van cruciale betekenis.

\section{Responsieve rechtsstaat ook beter voor de overheid}

Rekening houden met de burger zoals die echt bestaat, is niet alleen goed voor de burger, maar ook goed voor de overheid. Doordat de bureaucratische overheid de reactie van de burger verkeerd inschat, kan het beleid ineffectief en kostbaar worden, terwijl het veel beter zou kunnen. Dat is niet alleen een theoretisch inzicht dat door de WRR wordt vertolkt, maar blijkt ook uit experimenten in de praktijk. Die betreffen voor een aanzienlijk deel het innen van geldschulden, een uiterst belangrijk terrein waar overheid en burger met elkaar te maken hebben. Ook het WRR-rapport schenkt hier veel aandacht aan.

2 De Nobelprijs voor economie wordt om die reden ook toegekend aan wetenschappers die de link tussen economie en gedragswetenschappen hebben gelegd. Zo kreeg de gedragseconoom Richard Thaler, wiens inzichten over 'nudging' ook in het overheidsbeleid weerklank hebben gevonden, die prijs in 2017. 
Bij verschillende van die experimenten neemt de overheid als schuldeiser contact met de schuldenaar op wanneer die niet tijdig betaalt. De bedoeling daarvan is na te gaan of er iets aan de hand is met het doenvermogen van de schuldenaar, en hem daarbij zo nodig te ondersteunen. Het resultaat is dat er meer wordt betaald, er minder kosten worden gemaakt, en de schuldenaar minder vaak in een problematische schuldsituatie terechtkomt dan anders het geval zou zijn. Op de betekenis van dit voorbeeld wordt hieronder nog teruggekomen.

\section{Consequenties voor de wetgever}

Het WRR-rapport is goed ontvangen. De kabinetsreactie op het rapport is bepaald positief, ${ }^{3}$ en sommige voornemens uit het regeerakkoord van dit kabinet lijken door het rapport te zijn geïnspireerd. Voor alle geledingen van de overheid heeft het consequenties. In dit tijdschrift past het om vooral in te gaan op de gevolgen voor de wetgever. Toch moeten wetgever en uitvoeringsinstanties ook gezamenlijk optrekken: het verschil in doenvermogen tussen burgers vergt onderlinge afstemming van wet en uitvoering. Een van de middelen daarvoor is de kortgeleden opgerichte Regieraad Responsieve Overheid bij het ministerie van Binnenlandse Zaken en Koninkrijksrelaties (BZK), die wetgevers, uitvoerders en wetenschappers samenbrengt. ${ }^{4}$ Ook de laatsten zullen hun inbreng moeten leveren, waarbij de meer klassieke juristen en gedragswetenschappers synergie moeten zien te bereiken. Zoals de gedragswetenschappers de economische manier van denken hebben veranderd, zullen zij ook invloed op de inrichting van het recht moeten hebben.

Belangrijk voor de wetgever is dat hij bij het opstellen van regels rekening moet houden met het doenvermogen van de burger. Dat kan op verschillende manieren doorwerken in de architectuur van de wetgeving. De WRR geeft daarvoor een aantal handvatten, waaronder de gedachte om in de uitvoeringstoets voor regels het burgerperspectief te incorporeren. De (mentale) belasting van burgers, en ook de cumulatie van lasten als gevolg van verschillende regelingen, zou een belangrijk aandachtspunt moeten zijn. De WRR ziet daarbij ook veel in simulaties en experimenten voorafgaand aan de invoering van nieuwe regels, en in het opbouwen van kennis en ervaring in de doenlijkheid van regelgeving voor de burger.

Hiermee wordt een belangrijke aanzet voor verandering gegeven. De uitvoeringstoets, die nu vooral gericht is op de vraag of de overheid zelf de voorgenomen regels goed kan uitvoeren, zal ook gericht moeten zijn op de uitvoerbaarheid van de regels voor de burger. Dat is misschien minder eenvoudig dan het op het eerste gezicht lijkt. Of een regel voor de overheid uitvoerbaar is, kan men beoordelen aan de hand van een model van een goed werkende uitvoeringsorganisatie. De essentie van het rapport van de WRR is nu juist dat een soortgelijk modelbeeld van de burger niet mogelijk is. De burgers verschillen sterk van elkaar, en de bur-

3 Kamerstukken II 2017/18, 34775 VI, 88.

4 Zie onder meer de taakomschrijving in de kabinetsreactie, genoemd in de vorige noot, p. 8. 
ger die onder normale omstandigheden een regel goed kan hanteren, zal dat soms toch niet kunnen. Het perspectief van de burger is niet een eenduidig perspectief: het verschilt van burger tot burger, en kan ook voor één burger wisselen met de omstandigheden. Hoe moet men daarmee rekening houden?

De benadering zal hier meer lagen moeten bevatten.

\section{Eerste laag: hanteerbaarheid van de regel voor de doorsneeburger}

In de eerste plaats zal de hanteerbaarheid van de nieuwe regels voor de doorsneeburger moeten worden beoordeeld. Algemene regels blijven belangrijk, en veel regels zijn voor de meeste mensen goed hanteerbaar. Dan gaat het vooral om een zodanige architectuur van de regels dat zij voor zo veel mogelijk mensen goed te hanteren zijn. Daar ontbreekt het soms aan.

Een sterk voorbeeld daarvan is de manier waarop vroeger de beslagvrije voet bij de executie van schulden werd geregeld. Een ingewikkelde berekening was nodig om dat te doen, en de wetgever rekende er kennelijk op dat de schuldenaar die berekening zou kunnen maken. Dat kon bijna geen schuldenaar, waardoor deze bescherming voor hem in de praktijk slecht werkte.

Een ander voorbeeld betreft de ov-kaart waarmee studenten kunnen reizen. Na het einde van de studie moet de student de kaart zelf stopzetten, anders volgen er hoge kosten en boetes. Veel studenten vergeten dit te doen, en komen nodeloos in de schulden. Een alternatief zou zijn dat de overheid, die ook de beschikking heeft over de relevante gegevens, de kaart stopzet. Veel problemen worden dan voorkomen. De nieuwe minister van Onderwijs, Cultuur en Wetenschap (OCW) heeft inmiddels een belangrijke stap in die richting gezet, maar wordt beperkt door de manier waarop het hele systeem indertijd is vormgegeven. Had men direct deze toets gedaan, dan waren vele problemen voorkomen.

Een voorbeeld waar cumulatie van regels een probleem vormt, betreft het sociaal domein. Iemand die ondersteuning van de gemeente behoeft, heeft te maken met verschillende regels en verschillende uitvoeringsinstanties, zodat hij problemen niet op één plaats kan melden, maar van het kastje naar de muur wordt gestuurd. ${ }^{5}$

Dit zijn voorbeelden waaruit het belang van het beoordelen van het doenvermogen bij het ontwerpen van wetgeving duidelijk wordt.

In veel gevallen blijken het doenvermogen van de burger en de uitvoerbaarheid voor de overheid met elkaar samen te hangen. Soms leidt eenvoudige uitvoerbaarheid voor de overheid tot problemen bij de burger, zoals bij de ov-kaart voor studenten. Het zal dus vaak gaan om een afweging van de lasten voor de overheid en die voor de burger.

5 Vgl. advies-Scheltema over geschilbeslechting sociaal domein, te vinden op www.rijksoverheid.nl/ documenten/, en het themanummer van het Nederlands Tijdschrift voor Bestuursrecht 2018, afl. 1, waarin ook een verkorte versie van het genoemde advies is opgenomen (p. 4-7). 
Denkt men in deze richting door, dan verliezen sommige sterk in het bestuursrecht gewortelde regels hun vanzelfsprekendheid. Het onaantastbaar worden van een besluit nadat de termijn van zes weken voor bezwaar is verlopen, is in tweepartijenverhoudingen moeilijk als evenwichtig te beschouwen wanneer men het doenvermogen vanuit het perspectief van de burger in ogenschouw neemt. De korte termijn heeft een belangrijke functie in verhoudingen waarbij meer partijen betrokken zijn: de onzekerheid behoort dan niet te lang te duren. Die functie is er niet op dezelfde manier wanneer het gaat om een verhouding alleen tussen de overheid en een burger.

Geldschulden zijn daarvan het belangrijkste voorbeeld. In de gewone juridische verhoudingen van het privaatrecht gelden betrekkelijk lange termijnen voor het betwisten van vorderingen. In het bestuursrecht wordt de burger in een veel slechtere positie geplaatst: indien hij binnen zes weken niet reageert op een besluit van de overheid waarbij een vordering wordt vastgesteld, is dat besluit onaantastbaar. In de praktijk blijkt veelvuldig dat burgers er niet toe komen om binnen een korte termijn bezwaar te maken. Zij gaan er vaak van uit dat zij-als het menens wordt doordat echt ingevorderd gaat worden - nog kunnen aantonen dat de vordering niet rechtmatig is. Kennelijk sluit de korte termijn bij geldschulden onvoldoende aan bij het doenvermogen van veel burgers. Ik zie ook niet in waarom de overheid hier meer bescherming moet krijgen dan iedere andere schuldeiser in het privaatrecht, en meen dat het WRR-rapport een sterke argumentatie toevoegt om voor geldschulden tot een andere regeling te komen.

\section{Tweede laag: differentiatie van regel(toepassing) naar de persoon van de burger}

Een tweede laag bij de beoordeling van de hanteerbaarheid van regels voor burger betreft de vraag wat er moet gebeuren indien een regel wel geschikt is voor de meeste burgers, maar voor een aantal van hen toch niet, of in sommige omstandigheden niet.

Uit het WRR-rapport blijkt dat de redzaamheid van de burger sterk uiteen kan lopen, en ook naar omstandigheden kan verschillen. Daarbij is opleiding een minder doorslaggevende factor dan men zou verwachten: ook hoogopgeleiden kunnen emotioneel reageren en daardoor onverstandige keuzes maken. Voor welhaast iedereen geldt dat omstandigheden het doenvermogen sterk kunnen beïnvloeden. Stress is daarbij een belangrijke factor, en omstandigheden als ontslag, verlies van een partner of ziekte kunnen grote invloed hebben.

Dit gegeven plaatst ons als juristen en wetgevers wel voor een probleem. Regels die voor iedere burger op dezelfde manier gelden, zijn een uitdrukking van het gelijkheidsbeginsel en bevorderen de voorspelbaarheid van het overheidsoptreden. Differentiatie van regeltoepassing naar de persoon van de burger of de omstandigheden waarin hij verkeert, lijkt daar haaks op te staan. 
De betekenis van het gelijkheidsbeginsel is inderdaad groot. Ook voor het rechtvaardigheidsgevoel van de burger: de ervaring van ongelijke behandeling wordt als erg negatief gezien. Uit de praktijk van landen die minder een rechtsstaat zijn, blijkt ook hoe belangrijk regels zijn als bescherming tegen willekeur en corruptie. Het gelijkheidsbeginsel mag dus niet te gemakkelijk overboord worden gezet.

Tegelijkertijd maakt de benadering van het WRR-rapport duidelijk dat voor het gelijkheidsbeginsel het perspectief van de burger niet vanzelfsprekend hetzelfde is als dat van de overheid. De soort van gelijkheid die de overheid vanuit haar perspectief in regels vastlegt, kan een heel andere gelijkheid zijn dan die de burger ervaart. Zo is bij de inning van schulden iedereen die niet tijdig betaalt voor de overheid gelijk. De burger zal dat anders zien: hij zal een flink optreden tegen de bemiddelde wanbetaler toejuichen, maar ziet hetzelfde optreden tegen degene die altijd keurig betaalt maar dat een keer niet heeft gedaan in de stress van een echtscheiding als zeer onrechtvaardig. Gelijke regeltoepassing vanuit het overheidsperspectief is geen waarborg voor gelijkheid vanuit het burgerperspectief. Dat laatste is wat in een responsieve rechtsstaat moet gelden.

De gedachte dat differentiatie tussen burgers nodig is, dringt zich overigens op verschillende terreinen van het bestuursrecht al op. In het sociaal domein betekent het leveren van maatwerk dat juist uitdrukkelijk wel rekening wordt gehouden met de persoon van de burger en de omstandigheden waarin hij verkeert. Ook in het omgevingsrecht lijkt dit een belangrijk aandachtspunt te worden. De Raad van State heeft uitdrukkelijk op deze ontwikkeling gewezen, en aangegeven dat het (juridisch) denken over het gelijkheidsbeginsel aan herziening toe is. ${ }^{6}$ Het perspectief dat de WRR hieraan toevoegt, is dat het doenvermogen van de burger niet voor alle burgers gelijk is, en bovendien voor dezelfde persoon naar omstandigheden kan verschillen. Dat vergt een invulling van het gelijkheidsbeginsel op een manier die beter rekening houdt met hetgeen men in een concreet geval van iemand kan verwachten.

Men kan het ook enigszins anders benaderen. Indien iemand niet doet wat van een rationeel en goed geïnformeerd persoon verwacht mag worden, kan men twee verschillende conclusies trekken. Men kan veronderstellen dat die persoon een goed doordachte beslissing heeft genomen, en bijvoorbeeld welbewust zijn schuld aan de overheid niet betaalt, of welbewust de termijn voor bezwaar of beroep laat verstrijken. Dat is de soort conclusie die de overheid geneigd is te trekken. Een geheel daaraan tegengestelde, maar in het licht van de WRR vaak plausibeler, conclusie is dat de betrokken persoon kennelijk niet in staat is om een doordachte beslissing te nemen en uit te voeren. Anders zou hij dat wel hebben gedaan. Het is niet altijd eenduidig vast te stellen wat de juiste conclusie is, maar het voorbeeld laat wel zien dat de gevolgtrekking die de overheid geneigd is te maken, lang niet altijd de juiste is. Daardoor is het onjuist bij het vaststellen van de regels of van het beleid steeds van de eerste mogelijkheid uit te gaan.

6 Raad van State, En nu verder! Vierde periodieke beschouwing over interbestuurlijke verhoudingen na de decentralisatie in het sociale en fysieke domein, 30 september 2016, p. 30-32. 
Dat blijkt ook in de praktijk. ${ }^{7}$ Sinds kort wordt er bij de invordering van schulden door sommige overheidsorganisaties systematisch nagegaan hoe het echt zit: is er sprake van iemand die niet wil betalen of van iemand die niet kan betalen? Er wordt contact opgenomen met de schuldenaar, en de vraag wordt gesteld of hij soms hulp nodig heeft. De resultaten zijn verbluffend. In veel gevallen blijkt het stellen van de vraag, en het even meedenken met de problematiek van de schuldenaar, een gunstig effect te sorteren. Dan vermindert de stress voor iemand die het overzicht over zijn financiën verloren heeft en kan vaak een voor beide partijen goede oplossing worden gevonden. De differentiatie die zo gemaakt wordt, betekent dat ondersteuning geboden kan worden aan degenen die uit zichzelf in doenvermogen tekortschieten, en dat dwangmaatregelen alleen ingezet worden in gevallen waarin dat zinvol is. Het resultaat is voor overheid, schuldenaar en samenleving aanzienlijk beter. De overheid blijkt met minder kosten meer te kunnen innen, de schuldenaar wordt niet door dwanginvordering en de daarmee verbonden hoge kosten gedreven in de richting van multiproblematiek (met overigens weer hoge kosten voor de overheid). Voor de samenleving is het resultaat eveneens positief: de maatschappelijke kosten van iemand met een schuldenproblematiek zijn hoger dan men zou vermoeden (bijvoorbeeld kosten voor de werkgever).

Hier ligt ook een sleutel voor het vinden van een oplossing. Men kan niet in het verlengde van het WRR-rapport afzien van het stellen en handhaven van algemene regels. Indien men zorgt voor een goede architectuur van die regels, ook vanuit het burgerperspectief, zullen de meeste mensen daar goed mee kunnen omgaan, en de rechtsstaat kan ook niet zonder. Maar daaraan moet worden toegevoegd dat bij tekenen die erop kunnen wijzen dat de burger niet goed met de regel omgaat, niet voldoende redzaam is om dat te doen, daarop moet worden ingespeeld. Als er problemen met betaling van een schuld zijn, moet de eerste reactie van de overheid niet zijn dat de schuldenaar bewust niet betaalt en daartoe dus gedwongen moet worden. Het niet betalen moet in eerste instantie worden opgevat als een teken dat er iets aan de hand is. Immers, de gevolgen van niet betalen zijn voor de schuldenaar zo negatief, dat hij zeker zal betalen wanneer hij over voldoende doenvermogen beschikt. Meestal zal er dus iets aan de hand zijn.

De wetgever zal zich dit moeten realiseren. Ook al zijn regels in de meeste gevallen goed te hanteren, zij zullen voor sommige mensen of in sommige situaties te hoge eisen stellen. De wet kan dergelijke situaties niet allemaal voorzien en gaan regelen. De consequentie daarvan is dat de wetgever aanvaardt dat bij de uitvoering in bijzondere omstandigheden maatwerk moet worden geleverd. Dan kunnen de regels dus niet meer routinematig worden gevolgd, maar moet ondersteuning worden geboden of soms ook een oplossing worden gevonden waarbij afwijking van de regels nodig is. Kortom: dan moet er maatwerk worden geleverd.

$7 \quad$ Zie Handreiking Behoorlijke en effectieve invordering van geldschulden, gepubliceerd door Passend Contact met de Overheid (PCMO) van het ministerie van BZK, ook te vinden op https:// prettigcontactmetdeoverheid.nl. 
Bij de problematiek van de schulden zou dit betekenen dat de wetgeving moet voorzien in de mogelijkheid van maatwerk in afwijking van de wet. Dat zou leiden tot een algemene bepaling in de titel over geldschulden in de Algemene wet bestuursrecht (Awb), waarin voor dit soort gevallen niet alleen een betalingsregeling, maar ook een kwijtscheldingsmogelijkheid is opgenomen. Uit het eerder gegeven voorbeeld zou dit aan de orde kunnen komen indien duidelijk is dat de schuldenaar eenvoudig niet in staat is de gehele schuld te betalen. Het weigeren van kwijtschelding leidt dan snel tot een situatie waarin de schuldenaar afglijdt naar een multiproblematiek. Met doorgaans nog veel hogere lasten, ook voor de overheid.

Meer in het algemeen zou ik menen dat het bestuursrecht een algemene voorziening zou moeten hebben om differentiatie bij de toepassing van wettelijke regels mogelijk te maken in situaties waarin het tekortschietende doenvermogen van de burger dit vereist. Het gaat dus niet om een hardheidsclausule, maar om een voorziening die het burgerperspectief voldoende recht doet.

Dit roept wel ogenblikkelijk de vraag op hoe dan toch het gelijkheidsbeginsel overeind kan blijven, en willekeur kan worden voorkomen. De vraag dus naar het kader waarbinnen dit maatwerk geleverd kan worden. Evenmin als de Raad van State, die zegt dat er nader op gestudeerd moet worden, ${ }^{8}$ heb ik daar al een duidelijk antwoord op. Maar toch is er wel iets over te zeggen.

Dan neem ik artikel 3:4, tweede lid, Awb tot uitgangspunt: de nadelige gevolgen van een besluit mogen niet onevenredig zijn in verhouding tot de met het besluit te dienen doelen. Wanneer het gaat om de uitvoering van door de wetgever vastgestelde regels wordt in ons rechtssysteem doorgaans aangenomen dat de wetgever reeds een afweging heeft gemaakt: dwingende wettelijke regels laten dan geen ruimte voor afwijking van de wet op grond van artikel 3:4, tweede lid, Awb. De inzichten van het WRR-rapport dwingen mijns inziens om hier anders over te gaan denken. De wetgever maakt zijn regels, uitgaande van de gedachte dat mensen voldoende met die regels kunnen omgaan. Voor de gevallen waarin dat niet zo is, en waarin bovendien de nadelige gevolgen van de regeltoepassing niet meer in evenredigheid staan met het doel van die regeltoepassing, kan een goed wetgever - in een responsieve rechtsstaat - die regels niet bedoeld hebben. In die gevallen moeten uitvoerders niet worden gedwongen om regels toe te passen, terwijl zij zien dat die regeltoepassing tot contraproductieve resultaten leidt.

De conclusie kan hier zijn dat wetgeving, beleid en uitvoering meer rekening moeten houden met het gegeven dat de overheid algemene regels moet kunnen stellen, maar tegelijkertijd moet kunnen inspelen op de persoon en omstandigheden van de burger, wanneer die leiden tot een beperking van zijn doenvermogen. Omdat hier een spanning bestaat tussen wetgeving en uitvoerders, en de laatsten vaak geneigd zijn om sterk regelgeleid te werken, zou een algemene wettelijke bepaling hier uitkomst bieden. Die bepaling moet niet alleen ruimte bieden voor 
professioneel maatwerk, maar die ook voorschrijven indien dat nodig is voor het responsief karakter van de overheid. Ik denk aan de volgende bepaling in de Awb.

Artikel 3:4a

Indien de toepassing van een wettelijke regel leidt tot nadelige gevolgen die onevenredig zijn in verhouding tot de met die regel te dienen doelen, en de belanghebbende hiervan geen verwijt kan worden gemaakt, kan van de regel worden afgeweken voor zover dat nodig is om tot een meer evenwichtige regeltoepassing te komen.

Ik denk dat een dergelijke algemene bepaling nodig is om te voorkomen dat een wet leidt tot niet-voorziene en niet-aanvaardbare toepassingen. De Nationale ombudsman stuit regelmatig op dergelijke situaties, waarbij een goede oplossing niet binnen handbereik is omdat daarvoor wijziging van wet of regelgeving nodig is. Een voorbeeld is het rapport over vrouwen in de opvang, die door de complexiteit en ontbrekende coördinatie in de regelgeving verstoken blijven van inkomsten die hun wel zouden toekomen. Bijvoorbeeld omdat als officieel adres gehandhaafd blijft het adres dat de betrokken vrouw juist is ontvlucht. ${ }^{9}$

\section{Le droit à l'erreur, of het recht om een keer een fout te maken (Macron)}

Een interessante benadering komt in dit verband van de Franse president Macron. Zoals beloofd in zijn verkiezingscampagne komt hij met een wet waarin een droit à l'erreur wordt toegekend. Blijkens berichtgeving in de Le Figaro is een wetsvoorstel om dat te regelen op 27 november 2017 aan de Franse ministerraad aangeboden. De bedoeling is om niet routinematig tot het opleggen van een sanctie te komen bij een verzuim of een fout zonder dat opzet in het spel is. In plaats van een sanctie zou een advies of een waarschuwing bij de eerste overtreding op zijn plaats zijn. Bij opzet of bij herhaalde overtreding kan dan wel een sanctie worden opgelegd.

Deze benadering geeft blijk van een originele manier om het perspectief van de burger een groter gewicht te geven. Tegen de achtergrond van de ervaringen die met het innen van vorderingen zijn opgedaan, zou het goed mogelijk zijn dat langs deze weg het naleven van regels beter bereikt kan worden dan via het opleggen van sancties.

Overigens rijpt het inzicht dat niet iedereen altijd in staat is goed om te gaan met een regel van de wetgever, ook bij uitvoeringsorganisaties. Zo beweegt de discussie in de Manifestgroep, een verband van grote uitvoeringsorganisaties, ${ }^{10} \mathrm{zich}$ in de richting van het beginsel dat kleine fouten tot kleine gevolgen moeten leiden, en (alleen) grote fouten tot grote gevolgen. Deze maatvoering heeft de wetgever 
bij het bepalen van boetes en verhogingen bij het niet-tijdig betalen of geven van inlichtingen regelmatig uit het oog verloren.

\section{De derde laag: het belang van procedurele rechtvaardigheid}

De WRR besteedt veel aandacht aan het burgerperspectief bij het vormgeven van regels en beleid. Dat vergt van de wetgeving aandacht voor de architectuur van regels, maar ook voor de mogelijkheid van differentiatie en maatwerk bij het toepassen daarvan.

Daarnaast lijkt mij de invalshoek van de procedurele rechtvaardigheid een belangrijke toevoeging te kunnen zijn. Met dit begrip doel ik dan niet alleen op de vormgeving van procedures, maar breder op een zodanige bejegening van de burger dat hij ervaart dat hij door de overheid voor vol, dat wil zeggen als een volwaardig lid van de samenleving, wordt aangezien. Indien hij door de overheid serieus wordt genomen, en hij merkt dat zijn inbreng en zijn belangen een plaats krijgen in de besluitvorming door de overheid, en er naar hem wordt geluisterd, zal hij de overheid als responsief ervaren. De uitkomst van die procedure zal hij dan kunnen aanvaarden, ook als die negatief is. Juist in dat geval - bij een negatieve uitkomst - is de procedurele rechtvaardigheid van groot belang. Dit geldt zowel voor het vertrouwen in de overheid als voor het zich neerleggen bij de uitkomst en het daaraan eventueel uitvoering geven.

Procedurele rechtvaardigheid is van groter belang naarmate iemand meer onzeker is. In de huidige gecompliceerde samenleving wordt de regelgeving steeds ingewikkelder. De burger merkt dat hij nog maar een beperkt inzicht heeft in zijn rechten en verplichtingen. Hij zal dus bij zijn contacten met de overheid op een andere bron moeten afgaan dan eigen studie van wet- en regelgeving. Iemand die vertrouwen heeft in de wijze van optreden en de responsiviteit die de overheid uitstraalt, en ervan overtuigd raakt dat zijn inzichten en belangen serieus zijn genomen, zal sterk geneigd zijn het optreden van de overheid als gerechtvaardigd te aanvaarden. Onderzoekers stellen dat juist bij negatieve beslissingen de procedurele rechtvaardigheid van groot belang is.

Praktijkervaringen lijken dit te bevestigen. Bij de informele bezwaarprocedure volgens het model, uitgedragen door Passend Contact met de Overheid (PCMO), blijkt dat een goed vormgegeven responsiviteit niet alleen de procedure vereenvoudigt, maar ook als effect heeft dat de burger zich eerder als volwaardig gesprekspartner geaccepteerd voelt. ${ }^{11}$ Dat feit bevordert op zichzelf al het vinden van een oplossing.

Dit inzicht zou in de wetgeving meer tot uitdrukking moeten komen. Bij wijze van voorbeeld noem ik de bepaling in de Awb, waarin staat dat een belanghebbende niet over zijn bezwaar gehoord behoeft te worden wanneer dat kennelijk onge-

11 Eindrapportage pionierstraject mediationvaardigheden; resultaten, analyses \& aanbevelingen, Prettig contact met de overheid 2, Ministerie van BZK, 2010. 
grond is. ${ }^{12}$ De bepaling is ingegeven door de gedachte dat het horen nauwelijks nog relevant kan zijn voor de beslissing op bezwaar: het is al direct duidelijk dat het bezwaar nergens op slaat. Maar vanuit de gedachte van procedurele rechtvaardigheid kan men tot de tegenovergestelde conclusie komen: de betrokken burger is kennelijk zo slecht op de hoogte van zijn rechtspositie dat juist met hem een gesprek nodig is om het vertrouwen te geven of te herstellen dat de overheid serieus met zijn belangen omgaat. De ervaringen met de informele bezwaarschriftprocedure van PCMO zijn daarbij interessant: indien in deze gevallen toch wordt gehoord, blijkt dat soms heel zinvol. Bijvoorbeeld omdat een voor alle betrokkenen gunstige oplossing kan worden bereikt, alleen niet via de uitspraak op bezwaar. ${ }^{13}$

Dit gegeven is voor de inrichting van het bestuursrecht belangrijker dan het op het eerste gezicht lijkt. De gedachten die hiervoor zijn ontwikkeld, stuiten in het bestuursjuridisch denken op een belangrijk bezwaar: het belast de organisatie van de overheid en de rechterlijke macht met regels die meer differentiatie vereisen en daardoor ook aanleiding tot meer procedures kunnen geven. Een goede vormgeving van de procedurele rechtvaardigheid kan hier een tegenwicht bieden. Ervaart de burger een responsieve overheid, dan draagt dat sterk bij tot een vertrouwen in de besluitvorming door die overheid, en dus ook tot minder procedures daarover. De burger zal immers de vraag of hij een bepaalde beslissing aanvaardt, bijna nooit kunnen baseren op eigen studie van de regelgeving en de jurisprudentie. Hij moet dus afgaan op bronnen die hem vertrouwen inboezemen. De overheid die zorgt dat zij dat vertrouwen verdient, kan dan de belangrijkste bron zijn. In een responsieve rechtsstaat zou dat eigenlijk ook het geval moeten zijn. Naarmate dat vertrouwen slinkt, zal de burger naar andere bronnen omzien, en sneller zijn toevlucht zoeken in allerlei formele procedures. Het zou daarom goed kunnen zijn dat de overheid die de toegang tot geschilbeslechting bemoeilijkt en formaliseert meer conflicten uitlokt dan de overheid die vanaf een vroeg stadium serieus openstaat voor hetgeen de burger naar voren wil brengen.

\section{Conclusie}

Het WRR-rapport draagt belangrijke bouwstenen aan voor het vormgeven van een rechtsstaat die ook vanuit het burgerperspectief die kwalificatie verdient. De kabinetsreactie op het rapport is positief en omarmt verschillende voorstellen van de WRR.

13 Men moet er overigens ook op bedacht zijn dat de bezwaarschriftprocedure misbruikt kan worden door het indienen van een ongefundeerd bezwaar, bijvoorbeeld om tijd te winnen. Bij een responsieve overheid past het om meer maatwerk te leveren, ook in die zin dat een negatieve houding van de burger door kan werken in de reactie van het bestuur. Daarin past de reactie op onzorgvuldigheid van de kant van de burger zoals voorzien in de bepaling onder d van art. 7:3 Awb goed. In wezen zou een dergelijke bepaling overbodig moeten zijn, omdat men ook van de burger een zekere zorgvuldigheid mag verlangen. 
Om werkelijk resultaat te bereiken moet er nog veel veranderen. Dat geldt ook voor de wetgeving. Enkele mogelijkheden zijn in deze bijdrage verkend. Een verdere doordenking en verder onderzoek, waarbij ook een gedragskundige invalshoek niet mag ontbreken, zullen nodig zijn. Het is een mooie uitdaging om de vormgeving van de rechtsstaat nog beter ten dienste te stellen van de burger. 